\title{
Taste Bud Cell
}

National Cancer Institute

\section{Source}

National Cancer Institute. Taste Bud Cell. NCI Thesaurus. Code C13147.

Any of the three types of the cells that constitute the taste bud. They are classified as neuroepithelial (sensory) cells, supporting cells, and basal cells. 